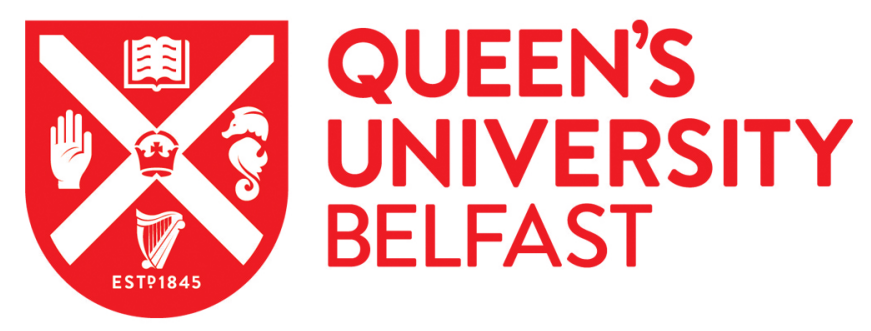

\title{
Graphitic-C3N4 coated floating glass beads for photocatalytic destruction of synthetic and natural organic compounds in water under UV light
}

Hui, J., Pestana, C. J., Caux, M., Gunaratne, H. Q. N., Edwards, C., Robertson, P. K. J., Lawton, L. A., \& Irvine, J. T. S. (2021). Graphitic-C3N4 coated floating glass beads for photocatalytic destruction of synthetic and natural organic compounds in water under UV light. Journal of Photochemistry and Photobiology A: Chemistry, 405, [112935]. https://doi.org/10.1016/j.jphotochem.2020.112935

Published in:

Journal of Photochemistry and Photobiology A: Chemistry

\section{Document Version:}

Peer reviewed version

Queen's University Belfast - Research Portal:

Link to publication record in Queen's University Belfast Research Portal

\author{
Publisher rights \\ (C) 2020 Elsevier Ltd. \\ This manuscript is distributed under a Creative Commons Attribution-NonCommercial-NoDerivs License \\ (https://creativecommons.org/licenses/by-nc-nd/4.0/), which permits distribution and reproduction for non-commercial purposes, provided the \\ author and source are cited.
}

\section{General rights}

Copyright for the publications made accessible via the Queen's University Belfast Research Portal is retained by the author(s) and / or other copyright owners and it is a condition of accessing these publications that users recognise and abide by the legal requirements associated with these rights.

\section{Take down policy}

The Research Portal is Queen's institutional repository that provides access to Queen's research output. Every effort has been made to ensure that content in the Research Portal does not infringe any person's rights, or applicable UK laws. If you discover content in the Research Portal that you believe breaches copyright or violates any law, please contact openaccess@qub.ac.uk. 


\section{Graphitic- $\mathrm{C}_{3} \mathrm{~N}_{4}$ coated floating glass beads for photocatalytic destruction of synthetic and}

natural organic compounds in water under UV light

Jianing Hui ${ }^{\text {a* }}$, Carlos J. Pestana ${ }^{b}$, Marine Caux ${ }^{\mathrm{a}}$, H. Q. Nimal Gunaratne ${ }^{\mathrm{c}}$, Christine Edwards ${ }^{b}$, Peter K. J. Robertson ${ }^{c}$, Linda A. Lawton ${ }^{b}$ and John T. S. Irvine ${ }^{a^{*}}$

${ }^{\text {a }}$ School of Chemistry, University of St Andrews, North Haugh, St Andrews, Scotland, KY16 9ST, UK.

${ }^{\mathrm{b}}$ School of Pharmacy and Life Sciences, Robert Gordon University, Garthdee Road, Aberdeen, Scotland, AB10 7GJ, UK.

c School of Chemistry and Chemical Engineering, the Queen's University of Belfast, Steanmillis Road, Belfast, Northern Ireland, BT9 5AG, UK.

Keywords: $g-\mathrm{C}_{3} \mathrm{~N}_{4}$, Floating photocatalysts, Microcystin-LR, Cylindrospermopsin, Dye degradation

\section{Abstract:}

Many drinking water reservoirs can contain organic pollutants such as artificial synthesized dye and drugs. On the other hand, some naturally occurring microorganisms such as cyanobacteria, are capable of producing toxic secondary metabolites (cyanotoxins) causing detrimental health effects in humans and animals are also present in water reservoirs. Photocatalytic destruction of organic pollutants in-reservoir requires not only good photo-catalytically activity but also efficacy of distribution and recycling. We report here, a facile calcination method of coating graphitic carbon nitride $\left(g-\mathrm{C}_{3} \mathrm{~N}_{4}\right)$ onto porous glass beads. Influences of precursor and heating temperature on photocatalytic activity were evaluated by photocatalytic degradation of methyl orange. The yellow floating beads show comparable activity to $\mathrm{P} 25\left(\mathrm{TiO}_{2}\right)$ coated beads in the removal of two of the most frequently occurring cyanobacterial toxins, microcystin-LR and cylindrospermopsin, in artificial freshwater under UV light irradiation. Microcystin-LR was destroyed within 60 min and cylindrospermopsin was removed after 100 min UV irradiation. The coated $g-\mathrm{C}_{3} \mathrm{~N}_{4}$ layer is very robust and shows negligible degradation on photocatalytic 
performance when recycled. The recycling of the photocatalyst is very simple because of the large size of the catalyst-coated beads. A large batch was successfully produced in a lab tube furnace. For further application, the ability of $g-\mathrm{C}_{3} \mathrm{~N}_{4}$ absorbing visible light could pave the way to utilise sunlight for the destruction of toxins in the water.

\section{Introduction}

Drinking water contamination caused by organic pollutants has been a worldwide concern. Synthetic pollutants that created as a result of human activity are easy to control by cutting off the pollution sources, while some organic compounds generated in nature are more complicated to deal with. Cyanotoxins due to algae blooms is one of the major threat to the safety of drinking water, especially in some developing countries. ${ }^{1}$ A large number of studies have been carried out on cyanobacterial toxin monitoring and management. Microcystin-LR (MC-LR) and cylindrospermopsin (CYL) are two of the most commonly occurring toxins found in reservoir water. ${ }^{2}$ MC-LR, a member of a group containing over 240 congeners, is a cyclic heptapeptide with two variable amino acid residue positions (see Fig. S1a). MC-LR has been reported in many lakes/reservoirs that provide drinking water, negatively affecting water quality. CYL is a polycyclic uracil derivative which contains both guanidino and sulphate moieties (see Fig. $\mathrm{S} 1 \mathrm{~b}) .{ }^{3}$ Both toxins are known to be relatively stable compounds, which makes them difficult to remove by conventional treatment methods when dissolved in the raw water.

Photocatalytic destruction is a promising technology to remove cyanotoxins within the reservoir using solar energy directly. ${ }^{4}$ On the surface of a semiconductor photocatalyst, hydroxide ions are oxidised to hydroxyl radicals $\left(\mathrm{OH}^{\circ}\right)$ at the valence band (VB). The photogenerated $\mathrm{OH}^{-}$radicals can oxidize a broad range of organic pollutants. Oxygen is reduced to superoxide radical anions $\left(\mathrm{O}_{2}^{--}\right)$at the conduction band $(\mathrm{CB})$. The $\mathrm{O}_{2}^{--}$anions may be protonated ultimately forming hydrogen peroxides $\left(\mathrm{H}_{2} \mathrm{O}_{2}\right)$, both of which are also oxidizing agents. ${ }^{5,6}$

Graphitic carbon nitride $\left(g-\mathrm{C}_{3} \mathrm{~N}_{4}\right)$ is a metal-free semiconductor, possessing carbon and nitrogen atoms arranged based on a tri-s-triazine unit. ${ }^{7,8}$ The ideal $g-\mathrm{C}_{3} \mathrm{~N}_{4}$ is constructed from highly conjugated two-dimensional sheets with a graphic structure in three-dimension. Because of the good thermal-, chemical-, and photostability of this material, as well as favourable band 
positions [ $\mathrm{CB}=-1.4 \mathrm{~V}, \mathrm{VB}=1.3 \mathrm{~V}$ vs. $\mathrm{Ag} / \mathrm{AgCl}$ at $\mathrm{pH} 6.6], g-\mathrm{C}_{3} \mathrm{~N}_{4}$ is suitable for visiblelight-driven water splitting and dye degradation. ${ }^{9-11}$ There have been some investigations on the photocatalytic destruction of cyanobacterial toxins over the past few years. ${ }^{12-16}$ Only a few studies were about $g-\mathrm{C}_{3} \mathrm{~N}_{4}$. Xu et al. ${ }^{16}$ reported $g-\mathrm{C}_{3} \mathrm{~N}_{4} / \mathrm{BiVO}_{4}$, a Z-scheme heterojunction, removed MC-LR efficiently under visible light using photo-generated hydroxyl radicals and superoxide radicals. However, the effect of a single $g-\mathrm{C}_{3} \mathrm{~N}_{4}$ photocatalyst (i.e. without invoking composite systems incorporating toxic metals) in cyanobacterial toxins destruction has not been studied yet.

One of the major drawbacks to the wide application of photocatalyst in real water such as reservoirs and rivers is the size of the photocatalyst. Most of the reported high activity photocatalysts are in the size of micrometres or even nanometres. The direct use of this kind of fine powders in water has potential danger to the environment. ${ }^{17,}{ }^{18}$ Moreover, most of these photocatalysts have a higher density than water, which means they will accumulate at the bottom of the reservoir in the absence of agitation. As light penetration is limited to the upper part of the water column obtaining light irradiation for these photocatalytic nanoparticles is problematic. One of the most promising strategies is to immobilize the active photocatalysts onto a floating substrate. ${ }^{19}$ Different types of substrates such as expanded perlite ${ }^{14,15,20}$, fly ash beads $^{21}$ and expanded polymer spheres ${ }^{22}$ have been used as photocatalysts substrates, however, these substrates have inherent disadvantages. For example, expanded perlite is very fragile because of its thin-walled structure. Coal fly ash is usually in micro-metre size, which is difficult to recover. The polymer substrates are also susceptible to degradation under UV light irradiation. Moreover, less stable substrates will further result in catalyst shedding during usage. Jingke Song et al. ${ }^{14,} 15$ reported effective inactivation of Microcystis aeruginosa (toxic cyanobacterium) using $\mathrm{C}_{3} \mathrm{~N}_{4}$ and $\mathrm{C}_{3} \mathrm{~N}_{4} / \mathrm{TiO}_{2}$ immobilized on expanded perlite, however, the photocatalysts showed an obvious shedding after a non-stirring test.

In this work, we used expanded glass beads with a porous inner core but relative dense shell structure for $g-\mathrm{C}_{3} \mathrm{~N}_{4}$ loading. These cheap glass beads are obtained during waste glass recycling and used as a lightweight building material. They present with good robustness and relatively regular surface for photocatalysts coating. A facile calcination method using a polymer precursor was used to obtain a $g-\mathrm{C}_{3} \mathrm{~N}_{4}$ coating layer. Optimization on coating process was 
carried out and the photocatalytic activity of obtained yellow floating photocatalysts was evaluated in dye degradation. To compare with the commercial $\mathrm{TiO}_{2}(\mathrm{P} 25), \mathrm{P} 25$ coated glass beads were prepared as a reference in the cyanobacterial toxin removal test.

\section{Experimental}

\subsection{Materials and chemicals}

Expanded glass beads (Diameter: 2 4 mm) were provided by Dennert Poraver $\mathrm{GmbH}$ (Germany). P25 ( $\mathrm{TiO}_{2}$, Rutile: Anatase/ 85: 15, 99.9\%, $20 \mathrm{~nm}$, from Aeroxide), thiourea (Sigma Aldrich, >99\%), dicyandiamide (Sigma Aldrich, 99\%), melamine (Sigma Aldrich, 99\%) and ethylenediaminetetraacetic acid (EDTA, Sigma Aldrich, ACS reagent) were used as received. Isopropanol (2-propanol, ACS, 99.5\%) was obtained from Alfa Aesar. Deionized (DI) water was used in all the experiment. MC-LR was obtained as per Edwards et al. ${ }^{23}$, CYL was obtained from Enzo Life Science, USA. Artificial freshwater was prepared according to Akkanen and Kokkonen ${ }^{24}$, in short $\mathrm{CaCl}_{2}\left(58.8 \mathrm{mg} \mathrm{L}^{-1}\right), \mathrm{MgSO}_{4}\left(24.7 \mathrm{mg} \mathrm{L}^{-1}\right), \mathrm{NaHCO}_{3}\left(13.0 \mathrm{mg} \mathrm{L}^{-1}\right)$, and $\mathrm{KCl}\left(1.2 \mathrm{mg} \mathrm{L}^{-1}\right)$ were dissolved in ultrapure water $(18.2 \mathrm{M} \Omega)$ and the $\mathrm{pH}$ adjusted to 7 with either $\mathrm{HCl}$ or $\mathrm{NaOH}$ (all chemicals were acquired from Fisher Scientific, UK).

\subsection{Preparation of $g-\mathrm{C}_{3} \mathrm{~N}_{4}$ coated glass beads}

Glass beads (used as received) were washed in an ultrasonic bath (Ultrawave U300H, SLS, UK) to remove any potential surface contamination with acetone and DI water, respectively. Clean beads were dried in an oven at $80{ }^{\circ} \mathrm{C}$ for further coating. For $g-\mathrm{C}_{3} \mathrm{~N}_{4}$ coating, wet beads $(3 \mathrm{~g})$ were mixed with the precursor $(1.2 \mathrm{~g})$ thoroughly to let the powder adhere to the surface of the bead. After that, the mixture was transferred into a custom-made aluminium crucible and covered with aluminium foil. The aluminium crucible was calcined in a muffle furnace at a temperature range from 450 to $600{ }^{\circ} \mathrm{C}$. Post calcination the $g-\mathrm{C}_{3} \mathrm{~N}_{4}$ coated beads were agitated gently in a stainless-steel sieve (pore size $1 \mathrm{~mm}$ ) and washed with water thoroughly to remove unattached $g-\mathrm{C}_{3} \mathrm{~N}_{4}$ particles. The loading amount is between $10 \mathrm{wt} \%$ and $15 \mathrm{wt} \%$ depending on different heating processes. 


\subsection{Preparation of $\mathrm{P} 25$ coated glass beads}

The same pre-treatment as described for $g-\mathrm{C}_{3} \mathrm{~N}_{4}$ coated glass beads was performed before coating with P25. The precursor turbid liquid was prepared by adding 1 g P25 nano-powder into $10 \mathrm{~mL}$ water. An ultrasonic bath was employed to break agglomeration and form a homogeneous suspension. Pre-treated glass beads were immersed into the precursor turbid liquid for $10 \mathrm{~min}$ with intermittent stirring. After this, the beads were removed from the precursor solution and dried in an oven at $80^{\circ} \mathrm{C}$. Coated beads were calcined at $550{ }^{\circ} \mathrm{C}$ to create a strong bonding between $\mathrm{TiO}_{2}$ and the glass beads. Each cycle of coating deposited about 2 $\mathrm{wt} \% \mathrm{TiO}_{2}$ catalyst. Repeated coatings were carried out to achieve a catalyst loading amount of more than $12 \mathrm{wt} \%$. The beads used in the present work present with a $\mathrm{TiO}_{2}$ loading of approximately $12 \mathrm{wt} \%$. Photos in Fig. S2 show $100 \mathrm{~g}$ batch achieved in a lab tube furnace with a uniform coating of $g-\mathrm{C}_{3} \mathrm{~N}_{4}$ and $\mathrm{P} 25$.

\subsection{Characterization}

The morphologies and elemental distribution analysis of coated glass beads were carried out on a scanning electron microscope (SEM, FEI Scios DualBeam) and its dispersive X-ray spectroscopy (EDX) module. The phase was confirmed by powder X-ray diffraction (XRD) on

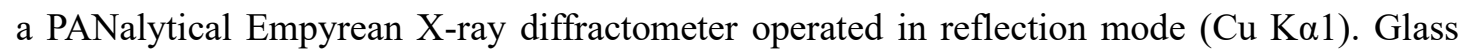
beads were ground to a powder using a pestle and mortar before performing XRD analysis. UVVis absorbance spectra were collected on an ultraviolet-visible spectrophotometer (JASCOV550). The BET (Brunauer-Emmett-Teller) surface area of samples was tested on a Micrometrics TriStarII 3020 instrument.

\subsection{Catalyst evaluation by photocatalytic dye degradation}

To optimize the $g-\mathrm{C}_{3} \mathrm{~N}_{4}$ coating process on glass beads, a custom-made multi-channels photoreactor was employed to run photocatalytic dye degradation experiments. As shown in Fig. S3a, a maximum of eight glass vial can be held in this reactor by a glass vial holder. A Fe doped metal halide lamp $(250 \mathrm{~W})$ was fixed $15 \mathrm{~cm}$ above the vial holder. To allow the same amount of light irradiation for each sample, a DC gear motor was used to rotate vial holder gently at a speed of $10 \mathrm{rpm}$. Cooling fans were fixed beside glass vials to maintain the 
temperature at $25^{\circ} \mathrm{C}$ during the reaction. Each glass vial was covered by a thin quartz glass window to prevent water evaporation. For methyl orange (MO) degradation, each glass vial was filled with $25 \mathrm{~mL} 6.5 \mathrm{mg} \cdot \mathrm{mL}^{-1}(0.02 \mathrm{mM}) \mathrm{MO}$ aqueous solution. The quenchers (isopropanol, ethylenediaminetetraacetic acid) were added by a volume ratio 1:100 to the solution. Samples $(500 \mu \mathrm{L})$ were withdrawn and analysed for dye concentration by UV-VIS absorbance at predetermined time intervals. The output spectra of metal halide lamp without and with UV cut-off filter ( $>400 \mathrm{~nm})$ were presented in Fig. S3b and 3c.

\subsection{Photocatalytic cyanotoxins destruction}

Photocatalytic degradation of selected cyanobacterial toxins was carried out in a custombuild photo-reactor. Four non-integrated fluorescent lamps (36 W each, Philips) were used as UV light sources, as shown in Fig. S4a. $300 \mathrm{mg}$ coated beads were suspended in $10 \mathrm{~mL}$ artificial freshwater with a toxin concentration of $10 \mu \mathrm{g} \cdot \mathrm{mL}^{-1}$. Magnetic stirring was applied to provide better diffusion. The temperature of the reactor was maintained at $25^{\circ} \mathrm{C}$ by using cooling fans. Samples $(200 \mu \mathrm{L})$ were withdrawn and analysed for remaining MC-LR by HPLC-PDA and remaining CYL by UPLC-PDA at predetermined time intervals. The output spectrum of the fluorescent lamp can be found in Fig. S4b.

\subsection{HPLC analysis of MC-LR and CYL}

HPLC analysis was performed on a Waters 2695 Separation Module. High-resolution photodiode array detection was performed with a Waters 2996 Photodiode Array Detector (PDA). Analysis of microcystin-LR was performed with a Symmetry C18 column $2.1 \mathrm{~mm}$ (inner diameter) x $150 \mathrm{~mm}$ with a $5 \mu \mathrm{m}$ particle size (all Waters, UK). The mobile phases used were ultrapure water (18.2 M $\Omega$ ) and acetonitrile (Fisher Scientific, UK), both containing $0.05 \%$ trifluoroacetic acid (Fisher Scientific, UK). Chromatography was achieved with a linear gradient from 15 to $75 \%$ acetonitrile over $10 \mathrm{~min}$, followed by a solvent wash and equilibration. The column temperature was set to $40{ }^{\circ} \mathrm{C}$ and the flowrate applied was $0.3 \mathrm{~mL} \mathrm{~min}{ }^{-1}$. Injection volume was $25 \mu \mathrm{L}$. Analysis of cylindrospermopsin was performed using a reverse-phase Atlantis dC18 column $2.1 \mathrm{~mm}$ (inner diameter) x $150 \mathrm{~mm}$ with a $5 \mu \mathrm{m}$ particle size (Waters UK). Acquity UPLC System with Xevo quadrupole time of flight (QTOF) mass spectrometry 
in series (Waters, Elstree, UK) The mobile phases used were ultrapure water (18.2 M 2 ) and methanol (Fisher Scientific, UK). Chromatography was achieved with a linear gradient from 2 to $10 \%$ methanol over $10 \mathrm{~min}$, followed by a solvent wash and equilibration. The column temperature was set to $40{ }^{\circ} \mathrm{C}$ and the flow rate applied was $0.3 \mathrm{~mL} \mathrm{~min}{ }^{-1}$. The resolution of the PDA was set to $1.2 \mathrm{~nm}$ and data was acquired over a range of 200 to $400 \mathrm{~nm}$ for both analytes.

\section{Results and discussion}

\subsection{Precursors for producing $g-\mathrm{C}_{3} \mathrm{~N}_{4}$}

Three precursors thiourea $\left(\mathrm{CH}_{4} \mathrm{~N}_{2} \mathrm{~S}\right)$, dicyandiamide $\left(\mathrm{C}_{2} \mathrm{H}_{4} \mathrm{~N}_{4}\right)$ and melamine $\left(\mathrm{C}_{3} \mathrm{H}_{6} \mathrm{~N}_{6}\right)$, with increasing carbon content, were used for $g-\mathrm{C}_{3} \mathrm{~N}_{4}$ coating. Based on previous studies on powder $\mathrm{C}_{3} \mathrm{~N}_{4}$ synthesis, the formation of $\mathrm{C}_{3} \mathrm{~N}_{4}$ from single carbon precursors such as urea and thiourea usually follows a continuous polymerization process with intermediate products of $\mathrm{C}_{2} \mathrm{H}_{4} \mathrm{~N}_{4}$ and $\mathrm{C}_{3} \mathrm{H}_{6} \mathrm{~N}_{6}$. The precursors sublime during the heating process and condense when forming a tri-s-triazine structure. The sublimation of the precursor or any intermediate products allows the $\mathrm{C}_{3} \mathrm{~N}_{4}$ to be coated onto the glass beads substrates.

Calcination of glass beads with thiourea, dicyandiamide and melamine at $500{ }^{\circ} \mathrm{C}$ for $5 \mathrm{~h}$, yielded coated $\mathrm{C}_{3} \mathrm{~N}_{4}$ beads with loadings of $0.7 \%, 9.8 \%$ and $14.3 \%$, respectively. Both dicyandiamide and melamine created a light-yellow coating layer upon glass beads. The glass beads calcined with thiourea showed no visible colour change. This could be expected, as thiourea, with the simplest structure, has much less chance to form polymer structure before decomposing in air. The morphologies of the coated glass beads using dicyandiamide and melamine were characterized by SEM, as shown in Fig. S5. Coating layers with rough surfaces were found on both samples. The coating layer prepared with melamine looked more porous than the one produced from dicyandiamide. Moreover, the holes on the glass beads were filled by polymer after coating indicating massive condensation during melamine sublimation.

X-ray powder diffraction was employed to check the crystal structure of the formed coating layer. The coated beads were ground into fine powder by mortar and pestle before analysis. A weak reflection peak at $27.6^{\circ}$ was determined in $g-\mathrm{C}_{3} \mathrm{~N}_{4}$ coated beads with both precursors (Fig. 1a). It is indexed as (002) corresponding to the aromatic stack plane. ${ }^{7,25}$ The sample prepared by melamine showed a higher peak intensity. This indicated a more crystalline 
structure. Moreover, the peak shifted to a higher angle, therefore, lower d spacing, which suggested tighter packing of the 2D tri-s-triazine sheets. The amorphous glass beads showed a 213 broad bump at the low angle region. Only a small reflection peak at $26.7^{\circ}$ was observed. More 214 than six impurity elements in the recycled glass beads were detected. It was difficult to identify 215 these due to the low peak intensity.

The absorbance properties of the yellow beads after coating were characterized by UVVIS diffuse reflectance spectroscopy (Fig. 1b). Almost the same absorbance curve was found in two different precursor coated samples, with a calculated bandgap around $2.65 \mathrm{eV}$. This is close to the pure $g-\mathrm{C}_{3} \mathrm{~N}_{4}$ reference material $(2.66 \mathrm{eV})$. The same light absorption region compared to powdered $g-\mathrm{C}_{3} \mathrm{~N}_{4}$ is expected in the photocatalysis test.

FTIR spectra revealed the chemical structure of coated $g-\mathrm{C}_{3} \mathrm{~N}_{4}$, as shown in Fig, 1c. A small broad bump at the $3000-3500 \mathrm{~cm}^{-1}$ region was attributed to the $\mathrm{N}-\mathrm{H}$ and $\mathrm{O}-\mathrm{H}$ stretches 223 from free amino groups and hydroxyl species. The strong band from 1200 to $1700 \mathrm{~cm}^{-1}$ resulted 224 from stretching and vibration of C-N and C-N-C bonds. ${ }^{26}$ Another sharp band observed at 806 $\mathrm{cm}^{-1}$ was attributed to the breathing mode of tri-s-triazine structure. ${ }^{27}$
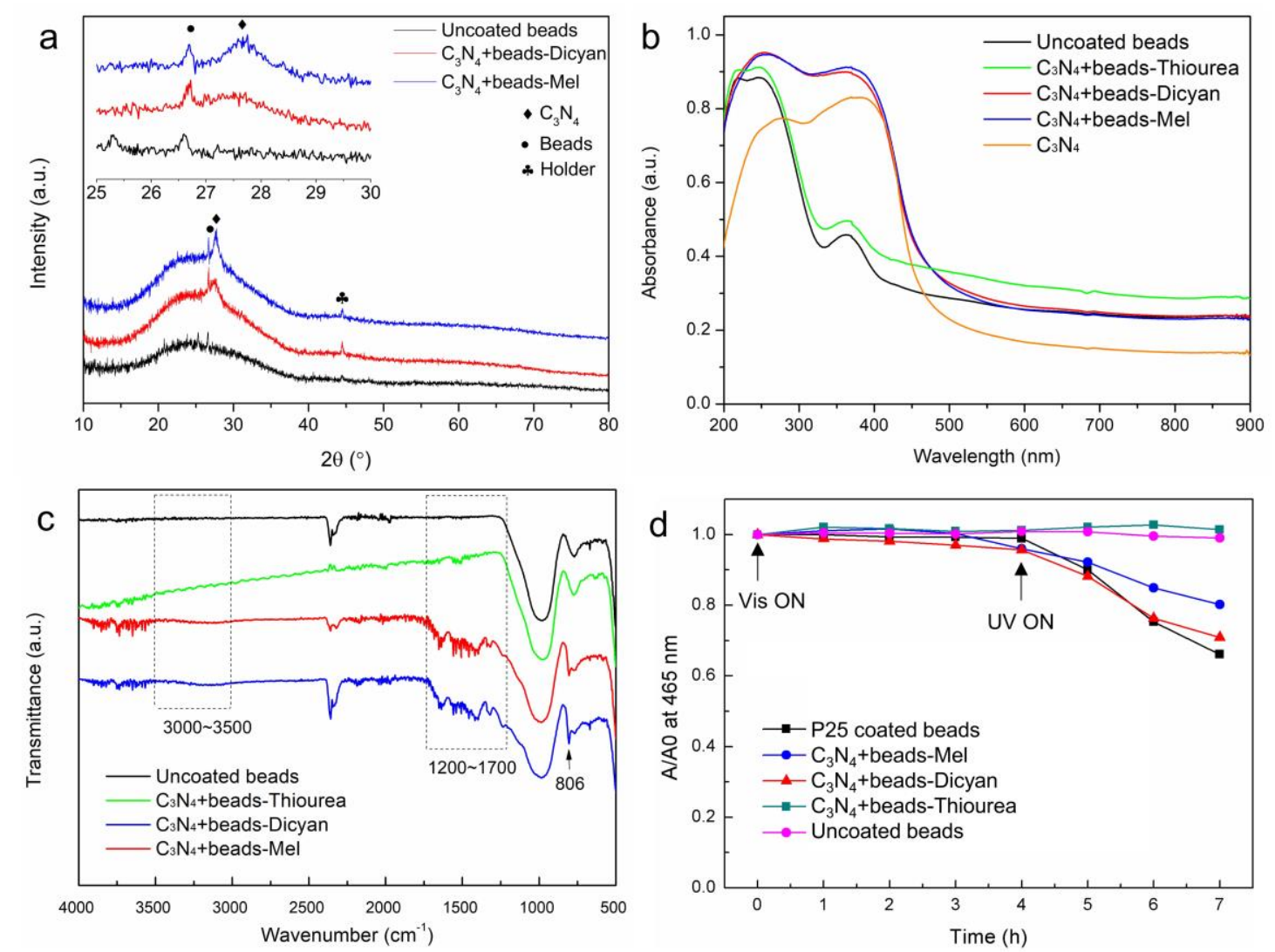
Figure 1. (a) X-ray diffraction pattern of uncoated and $g-\mathrm{C}_{3} \mathrm{~N}_{4}$ coated beads. Insert is the detail of $g-\mathrm{C}_{3} \mathrm{~N}_{4}(002)$ peak; (b) UV-VIS diffuse reflectance spectra of uncoated and $g$ - $\mathrm{C}_{3} \mathrm{~N}_{4}$ coated beads. Powder $g-\mathrm{C}_{3} \mathrm{~N}_{4}$ was added as a reference; (c) FTIR specta of uncoated and $g-\mathrm{C}_{3} \mathrm{~N}_{4}$ coated beads; (d) Normalized absorption intensity at $465 \mathrm{~nm}$ in methyl orange degradation using different coated beads. UVCUT 400 was removed after $4 \mathrm{~h}$. Samples were calcinated for $5 \mathrm{~h}$ at $500{ }^{\circ} \mathrm{C}$.

All the characterizations performed confirmed the successful coating of $g-\mathrm{C}_{3} \mathrm{~N}_{4}$ on expanded glass beads surface via simple calcination. The as-prepared yellow beads were used for methyl orange degradation to evaluate the photocatalytic activity. P25 coated beads were employed as a reference sample. As shown in Fig. 1d, all the samples exhibited poor photocatalytic activity under visible light $(\lambda \geq 400 \mathrm{~nm})$. Only melamine coated beads started to show dye degradation after $4 \mathrm{~h}$ irradiation. When switched to UV light $(\lambda \geq 250 \mathrm{~nm})$, beads coated with P25 and $g$ $\mathrm{C}_{3} \mathrm{~N}_{4}$ showed activity for methyl orange removal. P25 coated beads had the best performance, followed by $g-\mathrm{C}_{3} \mathrm{~N}_{4}$ coated beads prepared via dicyandiamide. $g-\mathrm{C}_{3} \mathrm{~N}_{4}$ coated beads prepared with melamine showed moderate performance, while the beads prepared with thiourea showed no activity compared to uncoated beads. One possible reason for the poor activity of $g-\mathrm{C}_{3} \mathrm{~N}_{4}$ coated beads under visible light is low light absorption. The UV-Vis absorbance curve shows coated beads have an absorption edge around $460 \mathrm{~nm}$, however, the maximum absorption appears until $370 \mathrm{~nm}$. This means when using a UV cut filter ( $\geq 400 \mathrm{~nm})$, the light-harvesting on the $g-\mathrm{C}_{3} \mathrm{~N}_{4}$ surface is much lower than when not using a filter. A $20 \%$ decrease of relative light intensity was also determined when checking the output spectrum with the spectrometer, which is another factor that causes low activity under visible light.

Although the dicyandiamide prepared $g-\mathrm{C}_{3} \mathrm{~N}_{4}$ coating layer showed better dye degradation performance under UV light, more shedding of the photocatalyst from the glass beads into the solution was observed during the test under continuous stirring. Considering the high yield and mechanical stability, melamine seems to be a better precursor for $g-\mathrm{C}_{3} \mathrm{~N}_{4}$ coating onto expanded glass beads. 
In our previous study, we found the calcination temperature in bulk $g-\mathrm{C}_{3} \mathrm{~N}_{4}$ synthesis had a significant influence on photocatalytic performance by affecting the crystal structure and electronic structure of $g-\mathrm{C}_{3} \mathrm{~N}_{4}$. Therefore, the calcination temperature for $g-\mathrm{C}_{3} \mathrm{~N}_{4}$ coating was also optimized in this work. ${ }^{25}$ Samples were prepared at 450 to $600{ }^{\circ} \mathrm{C}$ for $5 \mathrm{~h}$ with the same amount of melamine.

As shown in Fig. 2a, the peak intensity at (002) increased when the temperature rose from $450{ }^{\circ} \mathrm{C}$ to $500{ }^{\circ} \mathrm{C}$. An obvious peak shift to a higher angle in terms of lower d spacing was observed at $500{ }^{\circ} \mathrm{C}$. Both indicated improved crystallization with tighter packed $2 \mathrm{D}$ polymer sheets. When the temperature reached $550{ }^{\circ} \mathrm{C}$, the peak intensity decreased, which may be because the polymer structure started to decompose after $500{ }^{\circ} \mathrm{C}$. This was confirmed by thermogravimetric analysis (TGA) when heating bulk $g-\mathrm{C}_{3} \mathrm{~N}_{4}$ in air, as shown in Fig. S6. Due to this thermal decomposition, no reflection peak of $g-\mathrm{C}_{3} \mathrm{~N}_{4}$ was detected in samples prepared at $600{ }^{\circ} \mathrm{C}$, which meant most of the coated $g-\mathrm{C}_{3} \mathrm{~N}_{4}$ was burned off. The surface morphologies of these coated glass beads characterized by SEM showed this change in Fig. S7.
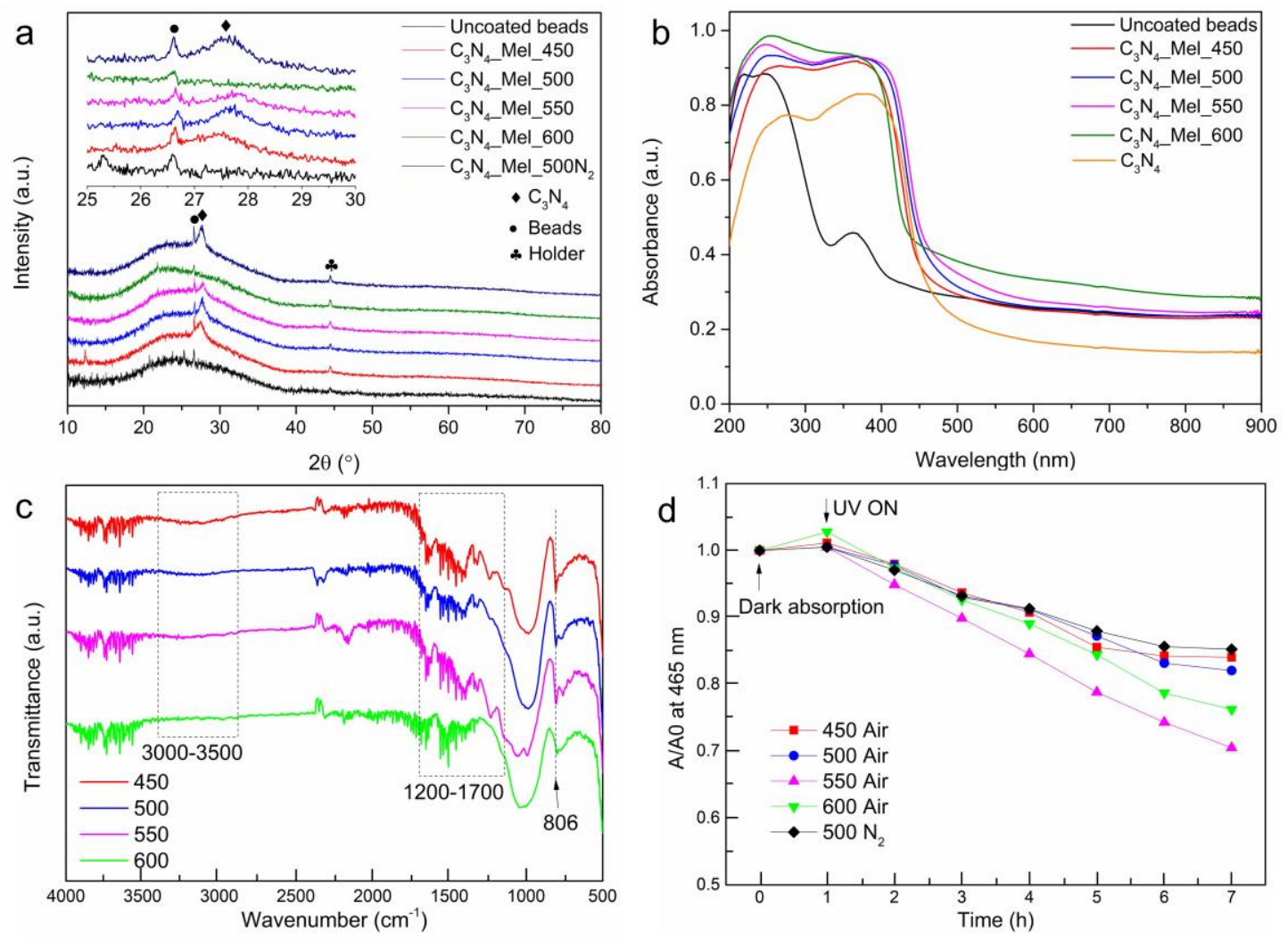

Figure 2. (a) X-ray diffraction pattern of uncoated and $g-\mathrm{C}_{3} \mathrm{~N}_{4}$ coated beads using melamine at different temperatures. Insert is the detail of $g-\mathrm{C}_{3} \mathrm{~N}_{4}(002)$ peak; (b) UV-VIS diffuse reflectance 
spectra of uncoated and $g-\mathrm{C}_{3} \mathrm{~N}_{4}$ coated beads at different temperatures. Powder $g-\mathrm{C}_{3} \mathrm{~N}_{4}$ was added as a reference; (c) FTIR spectra of $g-\mathrm{C}_{3} \mathrm{~N}_{4}$ coated beads at different temperatures; (d) Normalized absorption intensity at $465 \mathrm{~nm}$ in methyl orange degradation using coated beads prepared at different temperatures. UV light was switched on after $1 \mathrm{~h}$ dark absorption.

UV-Vis absorbance of coated beads presented a redshift as temperature increased from 450 ${ }^{\circ} \mathrm{C}$ to $550{ }^{\circ} \mathrm{C}$ (Fig. 2b). This suggested that a high annealing temperature is beneficial to form the crystalline structure of $g-\mathrm{C}_{3} \mathrm{~N}_{4}$, though parts of the polymer had been decomposed at 550 ${ }^{\circ} \mathrm{C}$. The sample prepared at $600{ }^{\circ} \mathrm{C}$ showed a blue shift as the decomposition domains and left little active material. Similar details were observed in the FTIR spectra in Fig. 2c. The sharp band at $806 \mathrm{~cm}^{-1}$ attributed to tri-s-triazine breathing mode showed the highest intensity at 550 ${ }^{\circ} \mathrm{C}$ and almost disappeared at $600{ }^{\circ} \mathrm{C}$.

Methyl orange degradation was carried out to evaluate the photocatalytic performance of coated beads. As shown in Fig. 2 d, the sample prepared at $550{ }^{\circ} \mathrm{C}$ showed the highest activity under UV light. It is surprising here that the sample calcined at $600{ }^{\circ} \mathrm{C}$ showed better performance than the beads prepared at a lower temperature $\left(450\right.$ and $\left.500{ }^{\circ} \mathrm{C}\right)$ though much less of the $g-\mathrm{C}_{3} \mathrm{~N}_{4}$ remained. This suggests the amount of active material may not be a key factor for photocatalytic activity because the reaction only occurs at the surface with incident light irradiation. A sample prepared in an $\mathrm{N}_{2}$ atmosphere at $500{ }^{\circ} \mathrm{C}$ was used for comparison here to elucidate the influence of the gas atmosphere. No obvious difference from a sample prepared in the air at the same temperature was observed. Good recycling performance was found when using $g-\mathrm{C}_{3} \mathrm{~N}_{4}$ coated glass beads prepared at $550^{\circ} \mathrm{C}$ for methyl orange degradation, as shown in Fig. S8.

\subsection{Catalysts distribution on glass beads}

EDS mapping was employed to check the elemental distribution on coated glass beads. $g$ $\mathrm{C}_{3} \mathrm{~N}_{4}$ coated beads presented uniform distribution of the $\mathrm{N}$ element layer on the top surface, as shown in Fig. 3c. Moreover, the $\mathrm{N}$ signal was detected inside the bulk of the beads. This revealed that intermediate products generated during $g-\mathrm{C}_{3} \mathrm{~N}_{4}$ formation diffused through the pores and condensed. This was a major difference to P25 coated glass beads in regard to active 
material distribution. Most of the coated P25 was located on the glass beads surface, as shown in Fig. S9. A thin layer containing Ti and O distributed uniformly on glass beads surface. XRD and UV-VIS absorbance confirmed the existence of the $\mathrm{TiO}_{2}$ phase. The backbone of the porous beads mainly contained Na, Si, Ca and $\mathrm{O}$, as shown in both $\mathrm{P} 25$ and $g-\mathrm{C}_{3} \mathrm{~N}_{4}$ coated beads.

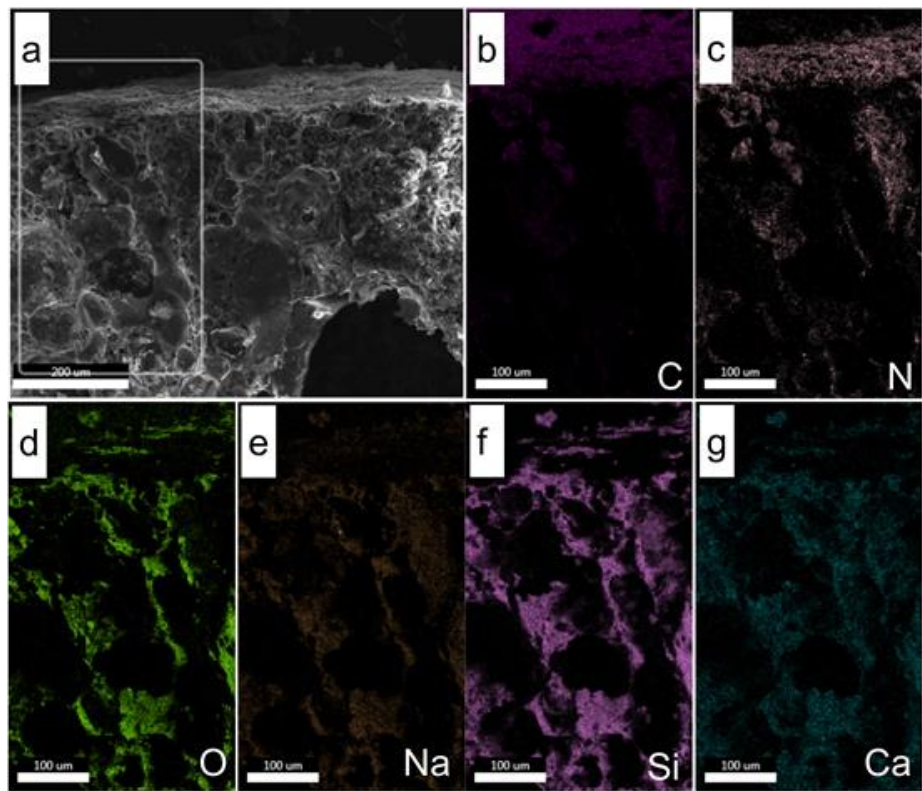

Figure 3. EDS mapping of $g-\mathrm{C}_{3} \mathrm{~N}_{4}$ coated glass beads at a cross-section. The sample was prepared with melamine at $550{ }^{\circ} \mathrm{C}, 5 \mathrm{~h}$. Scale bar is $200 \mu \mathrm{m}$ in (a) and $100 \mu \mathrm{m}$ in (b-g).

\subsection{Photocatalytic removal of cyanobacterial toxins}

The results obtained from both photocatalysts in the decomposition reaction of MC-LR and CYL are summarised in Fig. 4. In both cases, the coated beads were immersed in the solution containing the toxin for ten minutes in the dark for equilibration and allowing for dark absorption, before the commencement of irradiation. Controls are presented in the supplementary information. The $g-\mathrm{C}_{3} \mathrm{~N}_{4}$ coated beads used in this experiment were prepared at $550 \mathrm{C}$, with loading content around $12 \% \mathrm{wt}$. This is almost the same amount of loading of the P25 coated glass beads. The BET surface area of $g-\mathrm{C}_{3} \mathrm{~N}_{4}$ and P25 coated beads are $2.3 \mathrm{~m}^{2} \mathrm{~g}^{-1}$ and $2.6 \mathrm{~m}^{2} \mathrm{~g}^{-1}$, respectively. The $\mathrm{N}_{2}$ adsorption-desorption isotherms were presented in Fig. S10.

In the MC-LR removal experiment, both coated beads showed about 5\% toxin adsorption in dark. The reaction profiles after turning on UV light showed $g-\mathrm{C}_{3} \mathrm{~N}_{4}$ coated beads resulted in the complete removal of MC-LR 15 min earlier than the case with P25 coated beads. Control experiments in Fig. S11 showed neither catalysts in dark solution nor toxin solution in light 
without catalyst had any evidence of decomposition of the toxins.

In the case of CYL, a big difference in dark absorption was observed in the initial $10 \mathrm{~min}$ before photocatalysis. P25 coated beads absorbed 25\% CYL while $g-\mathrm{C}_{3} \mathrm{~N}_{4}$ coated beads absorbed $5 \%$ of the compound. The total time used for full removal of toxins was the same, which suggested the $g-\mathrm{C}_{3} \mathrm{~N}_{4}$ coated beads had a better photocatalytic efficiency compared to the P25 coated materials for CYL removal. Again, light control and dark control experiments were carried out, with both showing no CYL removal in Fig. S12.
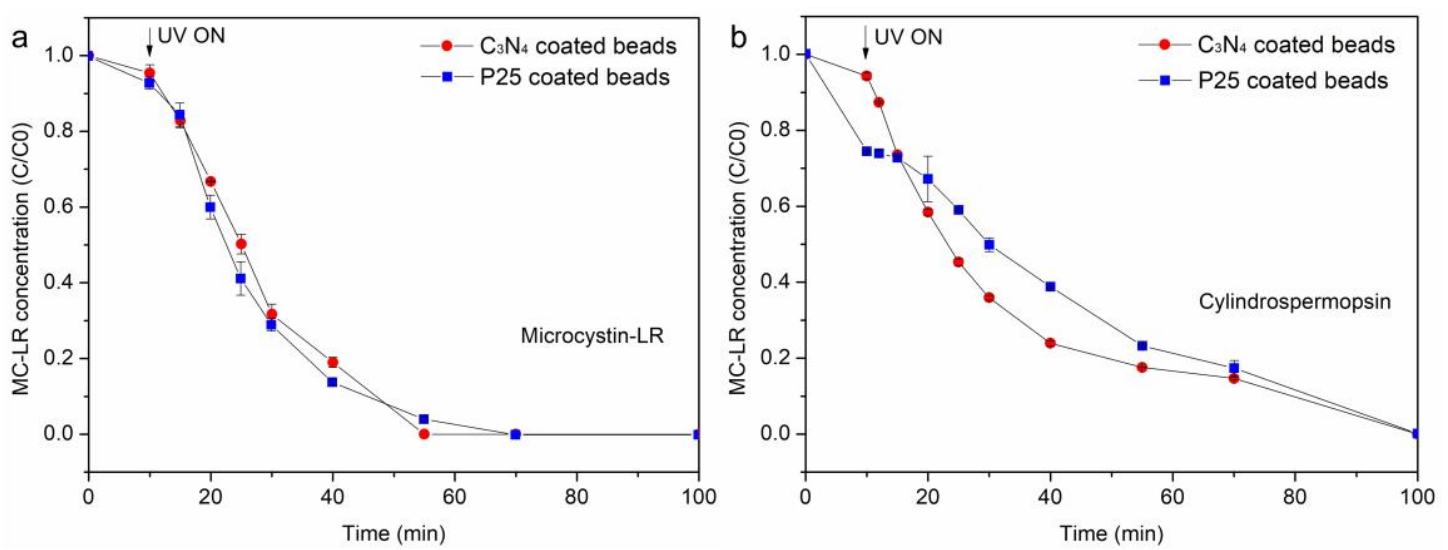

Figure 4. Graph showing the progress of photo-decomposition reactions of microcystin-LR (a) and cylindrospermopsin (b) with $\mathrm{TiO}_{2}$ and $g-\mathrm{C}_{3} \mathrm{~N}_{4}$ carried out at $25^{\circ} \mathrm{C}$ in an open photoreactor. g- $\mathrm{C}_{3} \mathrm{~N}_{4}$ coated glass beads in this experiment were prepared with melamine at $550{ }^{\circ} \mathrm{C}, 5 \mathrm{~h}$.

CYL is structurally very different to MC-LR lacking in any carboxylic acid groups and an oligopeptide macrocyclic structure. Due to the presence of a pendant strongly basic guanidine functionality in MC-LR, it is expected to abstract a proton from one carboxylic acid to form a zwitterion while leaving the second carboxylic acid group 'unionised'. It is well known that carboxylic acid groups have a binding affinity towards $\mathrm{TiO}_{2}$, thereby, making the photocatalytic process more feasible. Even without such binding functionalities CYL still underwent efficient photodecomposition with both photocatalysts. The kinetic profiles for the destruction of both toxins bore similarities despite the structural differences. It should be stressed that the absorption behaviour of CYL on the surface of $g-\mathrm{C}_{3} \mathrm{~N}_{4}$ is less well understood than MC-LR. Nevertheless, the photocatalytic performance of $g-\mathrm{C}_{3} \mathrm{~N}_{4}$ in the destruction process for both 
toxins used in this study was comparable to $\mathrm{TiO}_{2}$.

The weight of the catalysts was monitored before and after the test. When applying moderate stirring during the test, no obvious shedding was observed. A limited amount of $g$ $\mathrm{C}_{3} \mathrm{~N}_{4}$ shedding was, however, still found when stirring vigorously or using an ultrasonic bath. The TEM images in Fig. S13 show different shapes of $g-\mathrm{C}_{3} \mathrm{~N}_{4}$ shedding. EDS confirmed the composition are mainly $\mathrm{C}$ and $\mathrm{N}$. Nevertheless, shedding contamination can be avoided by washing the catalysts thoroughly to remove loose-packed active materials before use.

\subsection{Mechanism discussion}

Although $g-\mathrm{C}_{3} \mathrm{~N}_{4}$ coated glass beads have comparable performance to P25 coated ones, the mechanism for toxin removal and dye degradation are different. The photocatalytic removal of cyanobacterial toxins by $\mathrm{TiO}_{2}$ photocatalysts has been studied previously. ${ }^{28-30}$ The photogenerated hole at the valence band reacts with water to form hydroxyl radicals $\left(\mathrm{OH}^{*}\right)$, which have very high oxidation overpotential thus has the capacity of oxidizing a variety of organic pollutants. For $g-\mathrm{C}_{3} \mathrm{~N}_{4}$, the valence band is located negative to the $\mathrm{OH} / \mathrm{H}_{2} \mathrm{O}$ redox potential therefore unable to generate $\mathrm{OH}^{\circ}$. Only superoxide radical anions $\left(\mathrm{O}_{2}^{--}\right)$can be generated at the conduction band. The $\mathrm{O}_{2}^{--}$may subsequently react with protons $\left(\mathrm{H}^{+}\right)$to create $\mathrm{H}_{2} \mathrm{O}_{2}$. The generated $\mathrm{H}_{2} \mathrm{O}_{2}$ could be the source of hydroxyl radicals $\left(\mathrm{OH}^{\prime}\right)$. The processes to form $\mathrm{OH}^{*}$ have been illustrated in Fig. 5 and Eq. (1-4).

$$
\begin{aligned}
& \mathrm{O}_{2}+\mathrm{e}^{-} \rightarrow \mathrm{O}_{2}^{-} \\
& \mathrm{O}_{2}^{--}+\mathrm{H}^{+} \rightarrow \mathrm{HO}_{2}^{-} \\
& \mathrm{HO}_{2}^{\cdot}+\mathrm{e}^{-}+\mathrm{H}^{+} \rightarrow \mathrm{H}_{2} \mathrm{O}_{2} \\
& \mathrm{H}_{2} \mathrm{O}_{2}+\mathrm{e}^{-} \rightarrow \mathrm{OH}^{-}+\mathrm{OH}^{-}
\end{aligned}
$$

The $\mathrm{OH}^{\prime}$, with a largeoxidation overpotential, is believed to be the main radical that oxidizes organic pollutants during photocatalysis, though both $\mathrm{O}_{2}^{--}$and $\mathrm{HO}_{2}^{-}$are reactive. A comparison experiment was carried out using different quenchers in methyl orange degradation. As shown in Fig. S14, the addition of isopropanol, a $\mathrm{OH}^{\cdot}$ quencher resulted in a reduction of photocatalyst performance. This indicated $\mathrm{OH}^{-}$is essential to the degradation reaction. The addition of EDTA, a hole quencher improved the activity. This is because hole scavenger at the valence band inhibits electron-hole recombination. EDTA also introduced protons, which 

observed.

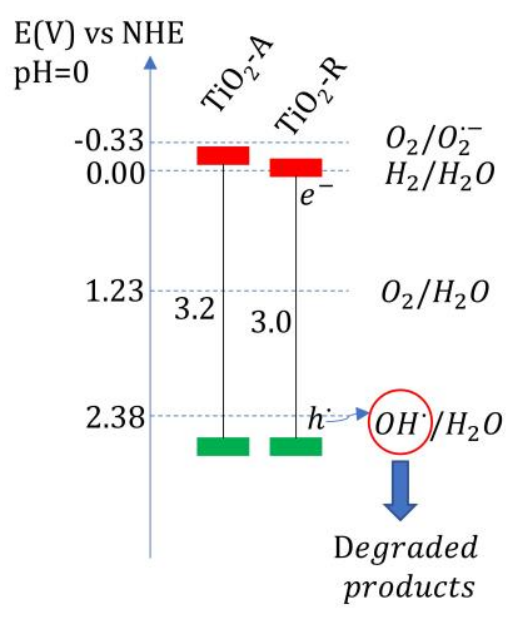

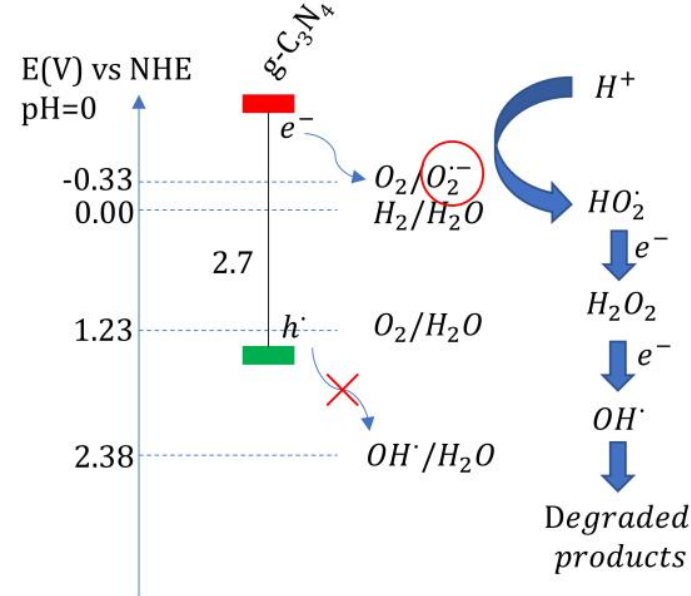

Figure 5. Proposed different mechanisms for toxin degradation in P25 and $g-\mathrm{C}_{3} \mathrm{~N}_{4}$ coated glass beads.

\section{Conclusions}

We have demonstrated, here, the comparable performance of a simple $g-\mathrm{C}_{3} \mathrm{~N}_{4}$ photocatalyst coated on floating expanded glass beads in comparison to traditional $\mathrm{TiO}_{2}(\mathrm{P} 25)$ photocatalyst for photo-removal of MC-LR and CYL from water. It must be stressed this simple $g-\mathrm{C}_{3} \mathrm{~N}_{4}$ is devoid of any detrimental metals and their insolubility in water makes it attractive materials for water purification. The floating material made recovery of the photocatalysts relatively easy which would allow for subsequent reuse. Moreover, the facile preparation process enables large batch production for full-scale application.

\section{Acknowledgements}

We acknowledge the funding provided by the Engineering and Physical Sciences Research Council, UK (Global Challenge Research Fund: EP/P029280/1) towards carrying out this research. We also thank the support on electron microscopes from EPSRC Capital for Great Technologies (Grant EP/LP017008/1 and EP/R02375/1).

\section{References}

1. K. Sivonen, in Encyclopedia of Microbiology (Third Edition), ed. M. Schaechter, Academic 
Press, Oxford, 2009, DOI: https://doi.org/10.1016/B978-012373944-5.00005-5, pp. 290-307.

2. I. Chorus and J. Bartram, Toxic Cyanobacteria in Water: A guide to their public health consequences, monitoring and management. 1999.

3. J. Fastner, R. Heinze, A. R. Humpage, U. Mischke, G. K. Eaglesham and I. Chorus, Toxicon, 2003, 42, 313-321.

4. L. A. Lawton and P. K. J. Robertson, Chemical Society Reviews, 1999, 28, 217-224.

5. M. Pirhashemi, A. Habibi-Yangjeh and S. Rahim Pouran, J Ind Eng Chem, 2018, 62, 1-25.

6. M. Shekofteh-Gohari, A. Habibi-Yangjeh, M. Abitorabi and A. Rouhi, Critical Reviews in Environmental Science and Technology, 2018, 48, 806-857.

7. F. Fina, S. K. Callear, G. M. Carins and J. T. S. Irvine, Chemistry of Materials, 2015, 27, 26122618.

8. A. Akhundi, A. Badiei, G. M. Ziarani, A. Habibi-Yangjeh, M. J. Muñoz-Batista and R. Luque, Mol Catal, 2020, 488.

9. X. Wang, K. Maeda, A. Thomas, K. Takanabe, G. Xin, J. M. Carlsson, K. Domen and M. Antonietti, Nature Materials, 2009, 8, 76-80.

10. S. C. Yan, Z. S. Li and Z. G. Zou, Langmuir, 2009, 25, 10397-10401.

11. Y. Cui, Z. Ding, P. Liu, M. Antonietti, X. Fu and X. Wang, Physical Chemistry Chemical Physics, 2012, 14, 1455-1462.

12. C. Huang, W. Zhang, Z. Yan, J. Gao, W. Liu, P. Tong and L. Zhang, RSC Advances, 2015, 5, 45368-45375.

13. F. Zhang, L. Wang, M. Xiao, F. Liu, X. Xu and E. Du, Journal of Materials Research, 2018, 33, 201-212.

14. J. Song, X. Wang, J. Ma, X. Wang, J. Wang and J. Zhao, Applied Catalysis B: Environmental, 2018, 226, 83-92.

15. J. Song, X. Wang, J. Ma, X. Wang, J. Wang, S. Xia and J. Zhao, Chem Eng J, 2018, 348, 380388.

16. Y. Xu, B. Hu, J. Liu, K. Tao, R. Wang, Y. Ren, X. Zhao, J. Xu and X. Song, Journal of the American Ceramic Society, 2019, 103, 1281-1292.

17. G. E. Schaumann, A. Philippe, M. Bundschuh, G. Metreveli, S. Klitzke, D. Rakcheev, A. Grun, S. K. Kumahor, M. Kuhn, T. Baumann, F. Lang, W. Manz, R. Schulz and H. J. Vogel, Sci Total Environ, 2015, 535, 3-19.

18. A. Praetorius, M. Scheringer and K. Hungerbuhler, Environ Sci Technol, 2012, 46, 6705-6713.

19. Z. Xing, J. Zhang, J. Cui, J. Yin, T. Zhao, J. Kuang, Z. Xiu, N. Wan and W. Zhou, Applied Catalysis B: Environmental, 2018, 225, 452-467.

20. S. Zhang, H. Li and Z. Yang, Materials Technology, 2017, 33, 1-9.

21. J. Lv, T. Sheng, L. Su, G. Xu, D. Wang, Z. Zheng and Y. Wu, Applied Surface Science, 2013, 284, 229-234.

22. S. Singh, H. Mahalingam and P. K. Singh, Applied Catalysis A: General, 2013, 462-463, 178195.

23. C. Edwards, L. A. Lawton, S. M. Coyle and P. Ross, J Chromatogr A, 1996, 734, 163-173.

24. J. Akkanen and J. V. K. Kukkonen, Aquat Toxicol, 2003, 64, 53-61.

25. M. Caux, F. Fina, J. T. S. Irvine, H. Idriss and R. Howe, Catalysis Today, 2017, 287, 182-188.

26. X. Yang, F. Qian, G. Zou, M. Li, J. Lu, Y. Li and M. Bao, Applied Catalysis B: Environmental, 2016, 193, 22-35. 
446

451

452

453

454
27. X. Bai, L. Wang, Y. Wang, W. Yao and Y. Zhu, Applied Catalysis B: Environmental, 2014, 152$153,262-270$.

28. L. A. Lawton, P. K. J. Robertson, B. J. P. A. Cornish, I. L. Marr and M. Jaspars, Journal of Catalysis, 2003, 213, 109-113.

29. C. J. Pestana, C. Edwards, R. Prabhu, P. K. J. Robertson and L. A. Lawton, J Hazard Mater, 2015, 300, 347-353.

30. L. X. Pinho, J. Azevedo, Â. Brito, A. Santos, P. Tamagnini, V. J. P. Vilar, V. M. Vasconcelos and R. A. R. Boaventura, Chem Eng J, 2015, 268, 144-152. 